\title{
DIREITO SOCIAL À SAÚDE NO ESTADO BRASILEIRO: ASPECTOS HISTÓRICOS E DESAFIOS CONTEMPORÂNEOS
}

\section{SOCIAL RIGHT TO HEALTH IN THE BRAZILIAN STATE: HISTORICAL ASPECTS AND CONTEMPORARY CHALLENGES}

\author{
${ }^{1}$ Têmis Limberger \\ ${ }^{2}$ Brunize Altamiranda Finger
}

\section{RESUMO}

O presente estudo objetiva analisar os principais aspectos históricos do direito à saúde no Estado brasileiro, a partir de 1930 - período em que os direitos sociais são criados em nível constitucional - até os dias atuais, dando-se enfoque ao fenômeno da judicialização da saúde nos últimos anos. Aponta-se fatores que poderiam estar relacionados a uma suposta incapacidade do Estado de realizar de forma plena este direito social. Utiliza-se o método histórico-evolutivo e o método dialético. Conclui-se que não é possível atender a todas as demandas e expectativas populacionais nesta área e previstas na Constituição com os recursos disponíveis atualmente.

Palavras-chave: Direito à saúde, Judicialização da saúde, Estado social, Crises

\begin{abstract}
This study aims to analyze the main historical aspects of the right to health in the Brazilian state, from 1930 - the period in which social rights are created - to the present day, giving focus to the judicialization of health. Points to factors that could be related to an alleged state's inability to perform fine form this social right. It is used the historical-evolutionary method, and the dialectical method. It is concluded that it can not meet all the demands and expectations population in this area and provided for in the Constitution with the resources currently available.
\end{abstract}

Keywords: Right to health, Judicialization of health, Welfare state, Crisis

\footnotetext{
${ }^{1}$ Doutora em Direito pela Universidade Pompeu Fabra, Barcelona, (Espanha). Procuradora de Justiça do Ministério Público do Rio Grande do Sul - MP/RS, Rio Grande do Sul. Professora do Programa de Pós-Graduação em Direito da Universidade do Vale do Rio dos Sinos - UNISINOS, Rio Grande do Sul (Brasil). E-mail: temis@ via-rs.net

${ }^{2}$ Mestranda no Programa de Pós-Graduação em Direito Público da Universidade do Vale do Rio dos Sinos UNISINOS, Rio Grande do Sul (Brasil). E-mail: brunizefinger@gmail.com
} 


\section{INTRODUÇÃO}

Os direitos sociais são direitos que se realizam através do Estado, isto é, o ente público deve proporcionar meios materiais para que os cidadãos possam efetivamente gozar de tais garantias. De modo geral, os direitos sociais ingressaram em nível constitucional no início do século XX - período em que as características de um novo regime estatal começaram a preponderar. Essa nova organização político-social, denominado de Estado Social, tem como padrão de conduta a intervenção estatal como forma de assegurar o bem- estar da população e a promoção da igualdade.

Nos anos 50 esse modelo de Estado expandiu-se de uma forma expressiva. Porém, nas décadas de 1970 e 1980, o sistema começa a se mostrar ineficiente na promoção de políticas sociais, o que leva esse regime estatal a apresentar crises. Pode-se dizer que a disputa pela efetivação dos direitos sociais (principalmente por meio de ações judiciais) é uma das principais marcas da contemporaneidade - sendo o direito à saúde um dos exemplos mais significativos.

No Brasil, os primeiros direitos sociais são criados a partir de 1930. Todavia, apesar desse movimento, não é possível afirmar que durante esse período o modelo de Estado em nosso país era de um Estado Social - como será analisado adiante. É com a promulgação da Constituição brasileira de 1988 que se pode visualizar as características mais consistentes de um Welfare State.

Dentre o rol de direitos sociais trazidos pela Carta Magna, a saúde é um dos que mais tem relevo na doutrina e jurisprudência. A criação do Sistema Único de Saúde é um dos marcos mais importantes na área de saúde pública. Entretanto, a não delimitação objetiva do conteúdo substancial do direito à saúde, aliada às dificuldades geradas pela escassez dos recursos públicos, tem levado as pessoas a ingressarem com ações judiciais para ver seu direito à saúde realizado. A judicialização da saúde é um dos grandes fenômenos que orbitam em torno desse direito social pós-88.

Atualmente, percebe-se que o direito à saúde - para quem tem a informação e a condição de acessar ao Poder Judiciário - tornou-se qualquer serviço ou medicamento que o indivíduo necessita para realizar o seu tratamento. Ao se efetuar pesquisa jurisprudencial em alguns Tribunais de Justiça do país é possível encontrar decisões que, com base no direito social à saúde, condenam o Estado a fornecer sessões de Pilates e RPG à pessoa que tem problemas posturais na coluna (RIO GRANDE DO SUL. Tribunal de Justiça, 2013); serviços de home care em tempo integral (SÃO PAULO. Tribunal de Justiça, 2016; MINAS GERAIS, 
Tribunal de Justiça, 2016, RIO DE JANEIRO. Tribunal de Justiça, 2016). Decisões que determinam que o Estado custeie tratamentos de alto custo, que não são oferecidos pelo Sistema Único de Saúde, e que, em alguns casos, não têm eficácia comprovada, acabam por um lado promovendo o direito à saúde de uns poucos e possivelmente causando maior restrição de acesso ao mesmo direito para outros - na medida em que os recursos são deslocados.

Percebe-se, portanto, que as problemáticas que permeiam o direito à saúde são muitas. Por conta disso, o presente estudo tem o objetivo de produzir uma análise dos principais aspectos históricos do direito à saúde no Estado brasileiro, a partir da década de 1930 - período em que os direitos sociais são criados em nível constitucional - até os dias atuais, dando-se enfoque à judicialização da saúde. É importante destacar que esta exposição não pretende ser uma referência completa, principalmente por conta da limitação de espaço. Em razão disso, optou-se por descrever os aspectos mais relevantes do direito à saúde no Brasil, não sendo possível aprofundar o tema aqui.

Para atingir esse objetivo utilizou-se o método histórico-evolutivo que auxiliou no acompanhamento da evolução do direito à saúde no Brasil, a partir de meados do século XX até os dias atuais. Também foi empregado o método dialético, pois o assunto em questão merece constante debate, tornando-se necessário o confronto de opiniões e correntes encontradas na doutrina e nos Tribunais. A técnica de pesquisa aplicada foi a bibliográfico- documental principalmente através de literaturas que versam sobre Estado Social, direitos sociais, direito à saúde e judicialização da saúde -, bem como legislação relativa ao tema.

\section{ESTADO SOCIAL: CONCEITO E ASPECTOS GERAIS}

Conforme o ideário do Liberalismo do século XIX observado na maioria dos países desenvolvidos daquela época, a intervenção do Estado em assuntos privados era exceção. Contudo, ao passo que aumentava o desenvolvimento econômico e tecnológico, fruto principalmente das práticas liberais, crescia a massa proletária urbana - com limitada capacidade para resolver determinados problemas em função da remuneração escassa, entre outras dificuldades - situação que exigia do Estado um papel mais atuante e significativo. Com isso, inicia-se uma transição entre formas de organização político-social: as características de um Estado Liberal deixam paulatinamente de preponderar, enquanto que a estrutura de um Estado que objetiva diminuir as desigualdades sociais e econômicas e promover o bem-estar de seus cidadãos aumenta. Nesse sentido, uma das experiências iniciais 
que começou a esboçar os primeiros traços do Estado Providência foi a plena intervenção estatal nas políticas de economia durante a Primeira Guerra Mundial. Nesse sentido, Streck e Morais (2000, p. 63) esclarecem que

\begin{abstract}
A derrocada do regime foi acelerada pela I Guerra Mundial, que transformou a face do mundo e iniciou novo capítulo nas relações econômicas. Surgiu a necessidade de o Estado atuar para organizar as necessidades produtivas, direcionando-as para o esforço de guerra, o que abriu caminho para uma experiência intervencionista concreta. A guerra provocou a destruição do mercado "natural" e ocasionou enormes perdas, requerendo a ação do Estado no sentido de evita-las, além de provocar o aumento numérico e o surgimento de uma consciência de classe entre os operários, cuja organização se intensificou nesta época, e cujo poder político passou a ser mais respeitado, possibilitando o enfrentamento dos proprietários dos meios de produção.
\end{abstract}

Outros fatores que contribuíram para o fim do Estado Liberal foram a Depressão de 1929, que demonstrou a necessária interferência do Estado na economia; o new deal proposto por Roosevelt nos Estados Unidos, em que o governo se interpôs no controle da produção agrícola, na regulação da jornada de trabalho, nos salários mínimos e nas negociações coletivas, etc.; e o voto universal, que possibilitou a participação no processo político de grande parte da população - população esta anteriormente excluída destas questões. Com isso, foi preciso elaborar propostas políticas que interessassem a esse novo eleitorado, principalmente que tratassem sobre assuntos econômico-sociais (STRECK; MORAIS, 2000, p. 59-61). Esses são alguns dos acontecimentos que permitem identificar tendências que originaram o Estado Providência; nesse sentido, Aureliano e Draibe detectam três grandes movimentos: (i) o desenvolvimento socioeconômico, principalmente em decorrência da industrialização e urbanização gerada pelo capitalismo de produção, (ii) a mobilização da classe operária e (iii) o desenvolvimento institucional, como a extensão do sufrágio (1989, p.

111).

O Estado Social é definido como uma organização político-social em que o cidadão tem o direito de ser protegido por meio de prestações públicas do Estado, sendo a promoção da igualdade e do bem-estar da população as principais razões para sua intervenção. Esse regime estatal também proporcionou a ampliação do conceito de cidadania ao assegurar direitos sociais (educação e assistência médica gratuita, auxílio em caso de desemprego, etc.), que são indissociáveis da condição cidadã. Além disso, as políticas sociais são encaradas como investimentos, e não como custos ou formas de "remediar a pobreza" - como eram no Estado Liberal. 
Frise-se que as políticas públicas não significaram apenas um meio de gerar a eficácia de direitos sociais, mas também uma necessidade da nova sociedade que estava se formando - pois, segundo Esping-Andersen, com a industrialização, "modos de produção préindustriais como a família, a igreja, a noblesse oblíge e a solidariedade corporativa são destruídas pelas forças ligadas à modernização, como a mobilidade social, a urbanização, o individualismo e a dependência de mercado" (1991, p. 91). Sabe-se, todavia, que o mercado destina-se apenas àqueles que conseguem atuar dentro dele, tornando assim inevitável a função de bem-estar social ao Estado-nação frente ao capitalismo.

Ademais, a garantia de determinados direitos e a promoção de políticas públicas promovidas pelo Estado Social não beneficiavam apenas a parte mais pobre da população. Conforme José Luis Bolzan de Morais (2011, p. 37), o processo de crescimento do papel do Estado também favoreceu o desenvolvimento de muitos setores; é o caso das estruturas básicas que alavancam o processo industrial, como a construção de usinas hidrelétricas, estradas e subsídios às iniciativas privadas.

Em termos de constituições, tem-se a Constituição do México de 1917 e a de Weimer de 1919 como as primeiras manifestações de um Estado de Bem-Estar Social (MORAIS, 2011, p. 39). Porém, apesar dessas Constituições estabelecerem uma espécie de marco jurídico do desenvolvimento de uma organização político-social denominada de Welfare State, o mesmo apresenta variadas trajetórias e formas de construção e expansão. É bem verdade, contudo - conforme ensina José Luis Fiori - que "quase todos os países, tipos e padrões seguiram uma evolução cujos grandes momentos e períodos são análogos porque estão determinados pela trajetória crítica do contexto mais amplo [...] em que se ambientou o welfare” (1997, p. 139). Em outras palavras, o modelo do Estado de Bem-Estar Social não apresenta uma origem bem delimitada e uma progressão linear, mas é possível observar padrões ou paradigmas originários de intervenção do Estado.

No Brasil e outros países da América do Sul, a conformação do Estado Social foi distinta da Europa e dos Estados Unidos - principalmente por causa da disposição das instituições legais e ideológicas, e do processo histórico. Em outros termos, apesar dos movimentos sociais que ocorreram, não foi possível uma transformação nos países com perfil de poder autoritário. Nesse sentido, Streck e Morais explicam que no Brasil

[...] não houve o Estado Social. O Estado interventor-desenvolvimentista-regulador, que deveria fazer esta função social, foi - especialmente no Brasil - pródigo (somente) para com as elites, enfim, para as camadas médio-superiores da sociedade, que se apropriaram/aproveitaram de tudo desse Estado, privatizando-o, dividindo/loteando 
com o capital internacional os monopólios e os oligopólios da economia [...] (STRECK; MORAIS, 2000, p. 73).

Exemplo disso foi a Política Habitacional que entre os anos de 1965 e 1984 produziu cerca de 4,5 milhões de casas, porém, apenas 723 mil destinaram-se às camadas de baixa renda (até três salários mínimos). Pode-se dizer que essa política foi uma das que teve o mais baixo grau de efetividade social (AURELIANO; DRAIBE, 1989, p. 135).

No que toca ao direito à saúde no Brasil, percebe-se que as ações e serviços visavam, quase que exclusivamente, a "remediar" a doença; não havia o planejamento para desenvolver um sistema que cuidasse da saúde da população. Em outras palavras, a intervenção estatal em questões de saúde não promovia o necessário bem-estar da população. Porém, ainda que não tenha havido um autêntico Estado Social no Brasil, percebe-se, a partir de 1930, intervenções estatais nos serviços de saúde - principalmente nas áreas que permitiriam um maior desenvolvimento econômico, conforme se poderá observar no tópico 3.

É com a Constituição de 1988 que se visualiza com mais nitidez um Estado Social brasileiro. Em diversas partes do texto constitucional nota-se um caráter intervencionista por meio de políticas públicas distributivas. Além disso, a própria redação do artigo $3^{\circ}$ reforça esse entendimento; esse dispositivo elenca dentre os objetivos fundamentais da República Federativa do Brasil a erradicação da pobreza e da marginalização, bem como a redução das desigualdades sociais e regionais. É portanto com o advento da Constituição de 1988 que se verifica um Estado comprometido a modificar a realidade brasileira.

\section{CRISES DO ESTADO SOCIAL}

No presente tópico será abordada a crise que vem fragmentando a estrutura do Estado Social, bem como algumas de suas consequências. Todavia, é preciso antes dedicar algumas linhas gerais para esclarecer a expressão crise do Estado.

O termo crise do Estado tem apresentado significados diferentes ao longo do tempo. Consoante Sabino Cassese, em um primeiro momento a crise do Estado dizia respeito ao surgimento de órgãos com um nível de força que começaram a colocar a prova a soberania estatal - como, por exemplo, sindicatos e grupos industriais. Posteriormente, a crise também passou a ser relacionada ao crescimento de poderes públicos internacionais que por vezes exerceram considerável controle sob o Estado. Atualmente pode-se dizer que a crise estatal, somada àqueles fatores, se traduz como a inadequação dos serviços do ente público frente às 
expectativas dos cidadãos, bem como a diminuição da participação do Estado em algumas atividades que tradicionalmente lhe competiam - é o caso das privatizações e concessões (2010, p. 13-14).

No que tange ao Welfare State, mostrou-se alhures que esse regime estatal tem como uma de suas características predominante a oferta de prestações sociais. Com o passar dos anos, contudo, percebeu-se que todo o leque de prestações sociais concedido aos cidadãos era economicamente inviável, o que foi sentido principalmente nos países que desenvolveram de modo satisfatório essa organização político-social - especialmente os países da Europa. Em outros termos, a estrutura do Estado Providência demonstrava não ser capaz de sustentar as suas promessas em razão principalmente dos elevados custos gerados pelas despesas sociais. Com a diminuição do Produto Interno Bruto, o Estado manifesta não ter toda a capacidade necessária para atuar como interventor da economia. Passa-se, então, a falar que o Welfare State começa a apresentar crises.

Segundo José Luis Bolzan de Morais, o Welfare State apresenta três crises: crise fiscal, crise ideológica e crise filosófica. ${ }^{1}$ A crise fiscal está relacionada aos diferentes níveis entre despesas públicas e produção nacional: os custos necessários para promoção de políticas sociais e redistributivas crescem num ritmo acelerado, o que não é acompanhado pela produção e arrecadação pública.

O descompasso entre receitas e despesas começa a mostrar seus primeiros sinais por volta dos anos 60. Mas é a partir de 1970 que a crise começa a tomar contornos mais evidentes, causada principalmente pela crise energética de base petroquímica. Segundo Morais, essa crise trouxe reflexos inexoráveis sobre as pessoas, pois isso acabou diminuindo a capacidade delas mesmas suprirem suas necessidades, o que exigia mais financeiramente do Estado. Ao crescer as despesas públicas, exigia-se mais tributariamente - levando a um círculo vicioso (2011, p. 44). Explicam Morais e Brum que as crises geradas por esse contexto econômico contribuíram para que políticas públicas provisórias passassem a ser permanentes, fazendo com que os gastos públicos fossem bem mais superiores à poupança do Estado Social, sendo o aumento da carga tributária ou a diminuição do oferecimento de prestações sociais duas possíveis soluções (2016, p. 16).

\footnotetext{
1 Além da crise estrutural (em que estão inseridas as crises do Estado Social), essa instituição político-jurídica também enfrenta uma crise conceitual, constitucional, funcional e política. Para um maior aprofundamento do tema, vide: MORAIS, José Luis Bolzan de. As crises do Estado e da Constituição e a transformação espaçotemporal dos direitos humanos. $2^{\mathrm{a}}$ ed. Porto Alegre: Livraria do Advogado, 2011.
} 
Observa-se desse modo que o impasse financeiro do Estado Providência está - dentre outros motivos - associado ao grau de socialização de bens e serviços que a sociedade está disposta a aceitar. Nesse sentido, Pierre Rosanvallon questiona: "há um limite sociológico para o desenvolvimento do Estado-providência e para o grau de redistribuição que o seu financiamento implica?" (1997, p. 15). Ainda segundo esse autor, na década de 90 os franceses arcavam com descontos obrigatórios na casa de 45\%. O relatório do VIII Plano francês elaborado à época - citado por Rosanvallon - exprimia a necessidade de rever os dispêndios com as políticas sociais, que crescia nitidamente mais que o PIB; do contrário, haveria um aprofundamento dos déficits públicos, afetando o equilíbrio da moeda nacional. Isso prejudicaria, segundo o relatório, a competitividade e, por consequência, o crescimento do país. Outra solução apontada por esse documento foi o aumento dos descontos obrigatórios, o que possivelmente diminuiria as margens das empresas e elevaria o preço dos produtos e serviços (ROSANVALLON, 1997, p 14).

Por conta disso, nos últimos anos surgiram correntes que propõem a necessidade de revisar as estruturas das políticas públicas que sejam economicamente sustentáveis. Todavia, Morais destaca que retornar a um modelo de Estado que deixe de intervir significativamente nas necessidades da população não é possível. O autor afirma:

[...] estamos diante de um ponto de não retorno. Não há como pensar-se em uma volta às bases de um Estado Mínimo incompatível com as demandas e necessidades de uma sociedade que se expande quantitativa e qualitativamente e que precisa dar conta de riscos que dizem respeito à própria possibilidade de desconstituição de laços sociais e da infraestrutura ecológica do planeta (MORAIS, 2011, p. 43).

Isso porém não quer dizer a proibição de rever algumas políticas - apenas que a desconstituição total das funções do Estado de Bem-Estar Social não é possível.

Além dos problemas financeiros, o Estado também enfrenta problemáticas em torno da sua legitimação - crise ideológica. A discussão repousa assim sobre as formas de organização e gestão do Estado Social, principalmente no que tange à burocracia como novo arranjo funcional.

Conforme Morais, a democratização do acesso ao espaço público político fez aumentar de forma significativa as demandas perante o Estado, bem como houve uma complexificação das pretensões sociais. Para responder a tais demandas, foi preciso constituir um corpo técnicoburocrático, invertendo a lógica ascendente da política democrática para uma lógica de verticalidade descendente (2011, p. 47). O mesmo autor ainda afirma: 
[...] ou se aumenta, expande e complexificam as fórmulas tomada de decisão democrática, em particular pela incorporação de novos mecanismos de participação e de autonomização social; ou se repensa os modelos de gestão das estruturas e serviços sociais (2011, p. 47).

Essa crise acaba refletindo na ineficiência do atendimento às pretensões sociais. Isto é, além da problemática em torno da manutenção das políticas sociais em decorrência do déficit financeiro, a disponibilização de serviços e ações que objetivam efetivar os direitos sociais são cada vez mais burocráticos, inviabilizando o oferecimento de um acesso rápido e completo.

Como consequência das duas crises analisadas anteriormente, apresenta-se a crise filosófica, que fragiliza um dos principais fundamentos do Estado Social: a solidariedade. Por consequência, o conteúdo dos direitos sociais acaba enfraquecendo também.

Explica Morais que, à medida que a capacidade financeira do Estado para investimentos públicos diminui, o mesmo acontece com o caráter solidário do grupo, “[...] passando a produzir-se uma disputa iníqua pela apropriação do que resta de pressupostos públicos" (2011, p. 48).

Tecidas essas breves considerações sobre crise do Estado e crises do Welfare State, é preciso destacar que a erosão da estrutura moderna do ente estatal não segue um processo linear, pois ela está condicionada principalmente a fatores históricos de cada país. No que tange ao Estado Social brasileiro - que começou a se expandir tardiamente -, é possível afirmar ele esteja atualmente enfrentando crises que outros países desenvolvidos talvez já tenham superado, ou parcialmente superado. Nesse sentido, pode-se identificar o fenômeno da judicialização da saúde - dentre outros eventos observados no cenário nacional - como uma consequência que decorre principalmente da crise do Welfare State brasileiro: em virtude da escassez dos recursos financeiros, o Estado não consegue oferecer um rol amplo de serviços de saúde e de medicamentos; isso tem levado as pessoas a buscar o Poder Judiciário para que esse direito social seja efetivado. Contudo, percebe-se uma série de pedidos a título de direito à saúde que são incompatíveis com o orçamento público ou que não constam na lista de serviços médicos e de fármacos oferecidos pelo SUS, o que possivelmente pode prejudicar o direito à saúde da coletividade ao restringir os recursos que seriam empregados em ações que atendem a um conjunto maior de indivíduos. Ressalta-se que a temática da judicialização da saúde será abordada no item 4 . 


\section{O PROCESSO DE CONSTRUÇÃO DE UM DIREITO À SAÚDE EM SOLO BRASILEIRO}

Até 1930 não se observa políticas nacionais de saúde no Brasil dispostas de maneira organizada e sistemática. O governo brasileiro começou a desenvolver algumas ações de saúde em razão da economia exportadora de café, predominante em meados do século XX. Essas ações estavam concentradas quase que exclusivamente no controle de endemias ${ }^{2}$ e de saneamento em portos e meios urbanos - principalmente no eixo agrário, formado pelos estados de São Paulo e Rio de Janeiro. Conforme o médico epidemiologista e pesquisador João Baptista Risi Junior, o público alvo das prestações sanitárias era a grande massa de trabalhadores do ramo cafeeiro, pois condições favoráveis da saúde dos trabalhadores significavam a garantia do sucesso econômico, assim como um atrativo para a mão de obra estrangeira (2002, p. 119).

Entre os anos 30 e 60, é possível verificar que a saúde passou por duas fases: a primeira foi a saúde pública e a segunda foi a medicina previdenciária. A primeira fase (saúde pública) caracterizava-se por ser um sistema centralizado na administração federal. Nesse período foi criado o Ministério da Educação e Saúde e, logo em seguida, o Departamento Nacional de Saúde e Assistência Médico-Social, que coordenava os departamentos estaduais de saúde (AURELIANO; DRAIBE，1989，p. 129). Esse Departamento desenvolveu, dentre outros, o Serviço Nacional da Febre Amarela (1937) e o Serviço de Malária do Nordeste (1939).

Entre 1945 e 1964, o Brasil vive um momento democrático em que é possível identificar algumas inovações no campo dos direitos sociais. É o caso do Ministério da Educação e Saúde que se tornaram Ministérios distintos, permitindo o desenvolvimento de novas ações em saúde - como, por exemplo, a criação do Departamento Nacional de Endemias Rurais (1956). Segundo Aureliano e Draibe, essa nova intervenção estatal objetivava ampliar o atendimento sanitário público à coletividade (1989, p. 130).

Já na década de 60 houve um acentuado declínio nos valores investidos na área da saúde pública. Uma das razões para essa diminuição de investimentos foi a falta de mobilização e força política da população, que não exercia pressão sobre o governo para que esse expandisse as políticas de saúde. Por conta disso, bem como por outros fatores, passou-se ao sistema da medicina previdência.

\footnotetext{
${ }^{2} \mathrm{O}$ controle de enfermidades girava em torno, basicamente, da febre amarela, peste bubônica e varíola.
} 
Com o aumento do número de trabalhadores, o sistema previdenciário expandiu-se, o que fortaleceu a lógica da medicina previdenciária. Criou-se o Instituto Nacional de Assistência Médica da Previdência Social (INAMPS), autarquia filiada ao Ministério da Previdência e Assistência Social (atualmente, Ministério da Previdência Social), que se destinava a prestar atendimento médico àqueles que contribuíam com a previdência social ou seja, empregados com carteira de trabalho assinada, especialmente as categorias profissionais do núcleo urbano-industrial. Quaisquer outras atividades que não envolvessem riscos em decorrência do trabalho ficaram sem patrocínio (KERSTENETZKY, 2012, p. 179).

Além disso, nesse período o governo começou a comprar serviços da área privada, o que acaba transformando a área de serviços médicos particulares um negócio próspero (KERSTENETZKY, 2012, p. 203). Esses serviços consistiam, basicamente, no atendimento emergencial à população não segurada - que, de modo geral, era formada por trabalhadores informais - enquanto que os serviços de atenção básica à saúde ficaram de lado. Percebe-se, desse modo, que a lógica do sistema era a cura da doença, e não o cuidado e a prevenção. Ademais, a prestação de serviços de saúde pelo setor privado fez com que uma influência corporativista predominasse no sistema. Aureliano e Draibe explicam:

[...] dada a privilegiada relação do sistema com o setor privado, prestador de serviços médicos, interesses particulares desse segmento, articulados com interesses burocráticos, fizeram-se muito presentes no processo decisório e de alocação de recursos. (1989, p. 131)

Portanto, a saúde na década de 60 e 70 serviu quase que exclusivamente para atender interesses privados, em vez de se ocupar das necessidades da população. Contudo, em 1984, essa tendência declinaria em razão de movimentos sociais que reivindicavam a reorganização do sistema de saúde no país. Tais movimentos resultaram na criação das Ações Integradas de Saúde (AIS) que objetivavam

[...] superar as características mais perversas, contraditórias e irracionais da política de saúde no Brasil, através de metas de integração das ações públicas nos três níveis da federação, do reordenamento da relação com o setor privado, da elevação da capacidade gerencial e otimização dos recursos financeiros do sistema e da descentralização de decisões e operação, visando, todas elas, a elevar o grau de eficácia e resolutividade da política e dos organismos responsáveis pela execução da atenção à saúde no país (AURELIANO; DRAIBE, 1989, p. 133)

Com as AIS a rede básica de serviço de saúde passou a se desenvolver por meio da regionalização do sistema. Para tanto, a coordenação da política de saúde ficou no âmbito 
municipal, regional e estadual, enquanto que em nível federal havia a Comissão Interinstitucional de Planejamento (PIMENTA, 1993, p. 26). O financiamento dos serviços era através de repasses de recursos da Previdência para as secretarias estaduais e municipais. Com isso, os resultados da implantação das AIS começaram a apresentar variáveis, pois estavam intimamente ligadas à realidade local. Mas, em regra, os recursos destinados às AIS não se mostraram suficientes para cobrir os gastos com a assistência médica.

Posteriormente surgiu o "movimento sanitário", que tinha como lema "Saúde e Democracia”. Esse movimento discutia a necessidade de reformular a saúde brasileira - o que seria possível se houvesse um rompimento com a lógica privatista. Com isso, as AIS se fortaleceram, o que possibilitou o surgimento do novo Sistema Unificado e Descentralizado de Saúde (SUDS), que procurou descentralizar mais ainda a gestão da saúde. Um dos maiores avanços desse novo sistema foi a elaboração de um Plano Diretor, que exigia de cada município um diagnóstico da realidade local e a relação de prioridades.

Com o advento da Constituição de 1988, novas mudanças ocorrem e um outro novo sistema é implantada, o Sistema Único de Saúde, que será abordado no item seguinte.

\section{O DIREITO À SAÚDE PÓS CONSTITUIÇÃO BRASILEIRA DE 1988}

A Constituição de 1988 representa um dos mais significativos avanços rumo a redemocratização do país. A chamada Constituição Cidadã assegura o direito à liberdade, igualdade, segurança, bem como um rol expressivo de garantias fundamentais. Quanto ao regime estatal, adota-se o modelo do Estado Democrático de Direito, que é um aprofundamento do Estado Social e do Estado de Direito. Nessa organização político-social há uma permanência do tratamento da questão social, adicionando-se uma finalidade transformadora - e não apenas assistencialista (MORAIS, 2011, p. 41).

Além disso, com a Carta Magna a atribuição de direitos desvinculou-se da lógica trabalhista - modificando a tendência que surgiu no período Vargas -, passando a ter um status político. Conforme Celia Kerstenetzky (2012, p. 182), os direitos passam a ser dos cidadãos, e não mais apenas dos trabalhadores membros de uma categoria profissional, o que pode ser constatado através dos investimentos feitos pelos governos: 
mais rápido que o produto e a população, correspondendo à garantia de uma série de novos direitos sociais e uma era de novas prioridades (KERSTENETZKY 2012, p. 211-212).

A saúde tornar-se um direito do cidadão, cabendo ao Estado promovê-la, protegê-la e recuperá-la por meio de políticas sociais e econômicas. O texto constitucional também prevê que as ações e serviços públicos de saúde integrarão um Sistema Único de Saúde (SUS). A saúde enquanto um dever do Estado engloba os três níveis da federação. Leciona Sueli Dallari (1995. p. 41):

\begin{abstract}
A Constituição da República Federativa do Brasil, promulgada em 1988, decidida a garantir o direito à saúde para todos, disciplinou as atividades governamentais com tal finalidade. Considerando que 'cuidar da saúde' é tarefa que a todos deve incumbir, elencou-a entre as competências comuns à União, aos estados, ao Distrito Federal e aos municípios (art. 23, II) e previu a competência legislativa concorrente sobre a proteção e defesa da saúde, limitando, a União ao estabelecimento das normas gerais, cabendo aos estados e aos municípios suplementá-las (art. 24, $\S 1^{\circ} \mathrm{e}$ $2^{\circ}$ c.c. art. 30, II).
\end{abstract}

Assim, em qualquer das esferas, o Poder Público não pode ser indiferente aos problemas de saúde dos cidadãos. Todavia, a implantação de normas gerais a um país de grandes dimensões geográficas e a existência de desigualdades regionais eram - e ainda são - umas das principais dificuldades enfrentadas pelo SUS. A fim de tentar reverter essa situação, bem como fornecer serviços de qualidade, em 2006 foi implantado o Pacto pela Saúde. Por esse plano, reforçou-se a descentralização e o município tornou-se o principal responsável pela gestão das ações e serviços oferecidos em seu território, proporcionando um atendimento focado nas necessidades da população local (BRASIL, 2006).

A implantação do SUS trouxe melhorias notáveis à população brasileira. Exemplo disso é o Programa Saúde da Família (PSF), que, no período de 1994 a 2016, passou de 300 equipes para mais de 48.400. Isso demonstra que há uma cobertura de aproximadamente 24 milhões de habitantes (60\% da população brasileira) (DEPARTAMENTO...). Apesar disso, o Sistema enfrenta dificuldades geradas principalmente pela falta de dinheiro público - e pela má gestão dos recursos, em algumas situações. Pode-se dizer que entre o previsto no projeto constitucional e a realidade econômica no Brasil há um descompasso que dificulta a efetivação plena de todos os direitos sociais. Contudo, conforme ressalta Morais,

Se das garantias constitucionais - ou das promessas constitucionais - emergisse a satisfação inexorável das pretensões sociais este debate, provavelmente, não se colocaria e tudo se resolveria por políticas públicas prestacionais e pela satisfação profunda dos seus destinatários, apesar de, como se tem visto da história do Estado Social, serem inesgotáveis as demandas - da satisfação de umas emergem a pretensão a outras (2011, p. 60-61). 
Essa insatisfação chega, então, ao Poder Judiciário, que muitas vezes é utilizado como uma tábua de salvação. Antes de aprofundar mais no tema, deve-se destacar que a discussão que se propõe no presente trabalho não é que as decisões dos Tribunais devam negar as demandas que visam à satisfação do direito à saúde. É preciso, porém, que a pretensão do requerente seja analisada conforme as políticas públicas de saúde existentes. Isto é, exigir judicialmente do Estado que forneça serviços e medicamentos previstos nas listas do SUS é medida que se faz necessária para efetivar o direito social à saúde.

Em contrapartida, a condenação do Poder Público para que forneça determinado serviço (como home care ou sessões de Pilates), ou remédio que não foi elencado na lista do SUS é uma decisão que fragiliza ainda mais a solidariedade (crise filosófica), valor base do Estado Social. Isso porque ao ser concedida uma tutela que atenda a um pedido mais complexo de uma minoria, a grande maioria poderá sofrer consequências graves - até mesmo a morte - em razão do deslocamento financeira que aquele pleito maior causará, já que não há dinheiro público suficiente para atender a todas as demandas da população (crise financeira). Ademais, a soma de tais pedidos e consequentes condenações torna o orçamento da saúde economicamente insustentável, acentuando mais ainda o descompasso entre a arrecadação e as despesas.

As medicações que são distribuídas no SUS, por exemplo, são regidas pela Política Nacional de Medicamentos, estabelecida pela Portaria $n^{\circ}$ 3.916/98. Por essa texto legal ficou estabelecido que os três níveis federativos, em colaboração, elaborariam listas de medicamentos a serem adquiridos e fornecidos à população. É tarefa do gestor federal desenvolver a Relação Nacional de Medicamentos (RENAME). Por conseguinte, o gestor municipal elabora a relação municipal de medicamentos essenciais baseando-se na RENAME, assegurando o suprimento de medicamentos voltados à atenção básica de saúde, bem como outros medicamentos essenciais, que foram definidos no Plano Municipal de Saúde (BARROSO, 2008, p. 23-24).

Ao julgar procedente os pedidos que requerem serviços e fármacos que extrapolam as listas do SUS, o Poder Judiciário estaria contrariando uma série de estudos e planejamento que priorizam medicamentos e serviços básicos voltados a atender às necessidades gerais da grande coletividade (BARROSO, 2008, p. 26). Em outros termos, ao condenar o Poder Público à realização de serviço ou entrega de determinado medicamento, o Judiciário acaba atendendo a uma necessidade imediata do litigante e possivelmente restringindo a satisfação das necessidades de outras pessoas, que seriam realizadas por meio de políticas públicas. Essa prática acentua as desigualdades em nosso país, pois privilegia aqueles que conhecem seus 
direitos e que podem arcar com as custas de um processo judicial - o que, de modo geral, beneficia mais a classe média do que as pessoas que pertencem a níveis econômicos inferiores.

Ademais, o artigo 196 da Constituição afirma que a saúde será promovida mediante políticas públicas e econômicas. Todavia, o que se tem observado é que a saúde, para uma minoria favorecida - principalmente os integrantes das classes econômicas mais elevadas, que sabem que podem pleitear esse direito junto ao Poder Judiciário, bem como detém a capacidade financeira para contratar advogado privado para tanto - tem sido satisfatoriamente promovida através de decisões judiciais. Nesse sentido, afirma Barroso:

\begin{abstract}
Pode-se entender que a melhor forma de otimizar a eficiência dos gastos públicos com saúde é conferir a competência para tomar decisões nesse campo ao Poder Executivo, que possui visão global tanto dos recursos disponíveis quanto das necessidades a serem supridas. Esta teria sido a opção do constituinte originário, ao determinar que o direito à saúde fosse garantido através de políticas sociais e econômicas. As decisões judiciais que determinam a entrega gratuita de medicamento pelo Poder Público levariam, portanto, à alteração do arranjo institucional concebido pela Constituição de 1988 (2008, p. 27).
\end{abstract}

Em regra, o Judiciário não tem a percepção técnica que o Poder Executivo tem para instituir políticas de saúde. Ao que parece, conforme destaca Ricardo Lobo Torres (2007, p. 360), ao contrário do que aconteceu com a receita pública, o Poder Judiciário entrega generosamente ações e serviços públicos, principalmente aqueles direitos de caráter social. Por outro lado, há quem defenda que, apesar do orçamento ter importância significativa, o mesmo não pode ser usado como um instrumento bloqueador da efetividade dos direitos fundamentais (BRANDÃO, 2007, p. 331).

De fato, o orçamento público não pode ser sempre usado como forma de defesa da Administração Pública quando esta for demandada por não efetivar direitos sociais. Porém, não se pode desconsiderado que os recursos na sociedade são escassos e que, portanto, escolhas devem ser feitas a fim de garantir ao maior número possível de pessoas o acesso aos bens e serviços produzidos. É verdade que a saúde não tem preço; tem, porém, um custo. E nem todos conseguem reconhecer os complexos custos empregados nos meios necessários para alcançá-la. Nesse sentido, um interessante campo da Economia vem ganhando espaço. Trata-se da Economia da Saúde, que busca obter o melhor estado de saúde - individual e coletivo - por meio dos recursos disponíveis (financeiros, humanos, tecnológicos e materiais). Aponta, ainda, como os custos podem ser minimizados para que seja alcançado os melhores níveis de 
assistência à saúde e as melhores condições de vida possíveis para determinado estado de saúde (VIANA; SILVA, 2011, p. 58).

Outro aspecto que deve ser considerado é que há um novo perfil epidemiológico, que acarreta um crescimento de gastos. Explicam Silva e Viana:

\begin{abstract}
A transição epidemiológica é caracterizada pela mudança no perfil de morbimortalidade da população. No lugar das enfermidades infecciosas e parasitárias, típicas de países com baixo grau de desenvolvimento, o novo perfil epidemiológico passou a incluir as chamadas doenças crônicas e degenerativas, como tumores, hipertensão, diabetes, problemas de saúde mental, entre outros, configurando um conjunto de patologias próprias de um modo de vida urbanoindustrial, cujo custo de tratamento é particularmente elevado. Além disso, o surgimento de novas doenças infecciosas, como a aids, tem imposto novos desafios aos sistemas de saúde em todo o mundo (2011, p. 184).
\end{abstract}

Ao se tratar do direito à saúde no Brasil é preciso que haja um comportamento racional, que haja um equilíbrio entre previsão orçamentária e previsão constitucional porque o conteúdo do direito à saúde - ensina Avelãs Nunes - sempre dependerá dos recursos financeiros constantes no orçamento do Estado, documento que espelha as decisões políticas tomadas para gerenciamento dos recursos públicos que serão aplicados em políticas públicas. Por isso,

[...] não se vê como aceitar que os tribunais possam caracterizar como incumprimento da Constituição a atitude do Executivo quando este, à luz da lei do orçamento aprovada pelo Poder Legislativo, alega não dispor de recursos públicos para atender a pretensão de quem recorre ao tribunal invocando o seu direito individual à saúde para pedir a condenação do Executivo (estado) a satisfazê-lo (NUNES; SCAFF, 2011, p. 40)

Em outras palavras, a concretização de direitos sociais depende de escolhas políticas, que farão a destinação necessária dos recursos financeiros disponíveis. Outrossim, ao deslocar recursos limitados - que estavam previamente destinados a outros serviços e meios de promoção da saúde coletiva - pode-se causar um impacto direito sobre a eficiência dos serviços e disponibilidade de medicamentos, que, por sua vez, possivelmente resultarão em consequências (negativas) para a população a que se destinava. A distribuição é característica do Estado Social. Porém, conforme adverte Manuel García-Pelayo, para que haja uma distribuição permanente de algo é preciso ter poder de disposição sobre este algo, bem como garantir sua produção e reprodução (2009, p. 23). Além disso, a distribuição deve ser operacionalizada conforme a realidade fática do país.

Sabe-se que uma parcela dos direitos sociais que estão consagrados no texto constitucional não é cumprida de forma plena pelo Poder Público. Todavia, nota-se que o pleito dos demandantes busca determinado conteúdo dos direitos sociais que não são previstos pelos textos legais; com isso, tais direitos acabam sendo artificialmente ampliados pelo Poder 
Judiciário, aumentando ainda mais as expectativas e exigências da população face ao Estado. Conforme MORAIS e BRUM explicam, não são legítimas as decisões do Poder Judiciário que concedem "desejos egoísticos travestidos hermeneuticamente de direitos constitucionais" (2016, p. 105). É preciso levar em consideração a crise financeira pela qual passa o Estado.

\section{CONSIDERAÇÕES FINAIS}

O presente estudo tinha como objetivo fazer uma retomada histórica do direito à saúde a partir dos anos 1930 até a Constituição de 1988. Após, foi realizada uma análise crítica sobre a judicialização da saúde, um dos principais assuntos que giram em torno da efetivação desse direito social. Com isso, foi possível observar que uma das principais problemáticas que envolvem a garantia à saúde é a ausência de uma definição objetiva do conteúdo substancial do direito à saúde; verificou-se também que não é possível atender a todas as demandas e expectativas populacionais nesta área e previstas na Constituição com os recursos disponíveis atualmente.

O primeiro ponto abordado neste trabalho foi o regime estatal adotado em que o Poder Público incumbiu-se de desenvolver medidas que promovessem o bem-estar e a igualdade dos seus cidadãos, principalmente por meio de ações prestacionais. Todavia, a partir de determinado momento, já não era possível atender a todas as demandas da sociedade. Por conta disso - bem como por outros fatores - o Estado Providência começa a apresentar sérias dificuldades, sendo o impasse financeiro a que mais afetou as prestações sociais. No Brasil, em um primeiro momento, não se desenvolveu um "verdadeiro" Estado Social porque suas intervenções não resultaram em bem-estar à população, nem diminuição da desigualdade.

Posteriormente passou-se a análise da evolução do direito à saúde no Brasil. Identificou-se que esse direito social inicialmente estava relacionado à questão trabalhista, ou seja, a saúde do trabalhador recebia mais investimento e atenção do que a saúde do restante da população. É possível, todavia, observar momentos em que o governo desenvolveu medidas com tendências mais universais - principalmente entre os anos de 1945 a 1964, período que o país viveu uma breve democracia. Ao sobrevir a Constituição de 1988, a saúde passou a ser um direito de todos e um dever do Estado - o que resultou em grandes mudanças. Pode-se avaliar que a criação do Sistema Único de Saúde tem gerado muitos benefícios à saúde dos brasileiros; porém o SUS apresenta deficiências em determinadas áreas, não conseguindo atender de forma plena os cidadãos. 
Concluiu-se que uma das principais causas que inviabiliza a efetivação plena do direito à saúde no Brasil é a escassez dos recursos públicos, bem como a ausência de um conceito objetivo desse direito social; outros possíveis motivos que dificultam a ampliação da eficácia do direito à saúde, bem como reforçam a sua judicialização são o baixo investimento que o governo faz na área da saúde pública e, em alguns casos, o não repasse da quantia mínima previamente estabelecida em lei. Mais um fator que pode contribuir para a não concretização plena do direito à saúde é uma possível desarmonia entre criação legislativa e realidade fática. Isto é, por vezes, o Legislativo cria leis que o Poder Executivo não consegue efetivar de maneira imediata e/ou plena em razão, por exemplo, da falta de recursos financeiros e técnicos. É o caso da Lei 12.732/2012, que garante o início do tratamento dos pacientes com câncer em até 60 dias após o diagnóstico. Contudo, é sabido que há unidades de saúde que sequer conseguem oferecer os serviços de Atenção Básica aos usuários do SUS; em São Paulo, por exemplo, para que a população consiga agendar uma primeira consulta com médico cirurgião, é preciso aguardar mais de 200 dias na fila de espera (ESPERA...,2014). Em outros termos, há situações que o Poder Legislativo acaba gerando muitas expectativas nos cidadãos por meio de leis que asseguram variados direitos, sem talvez estabelecer um diálogo com o Executivo a fim de refletir sobre a questão econômica e tecnológica que a lei demandará para ser executada. Ressalta-se que não se defende que cesse o desenvolvimento de novas leis que asseguram garantias fundamentais e sociais - como é o caso Lei 12.732/2012. O que se propõe é que haja uma maior interlocução entre os poderes, a fim de que determinadas propostas legislativas sejam mais coerentes à realidade orçamentária do país, bem como para que o Executivo possa fazer uma gestão mais eficiente dos recursos disponíveis, tornando a eficácia dos direitos a mais ampla possível dentro da realidade do país.

Esse cenário favorece que alguns indivíduos busquem junto ao Poder Judiciário a satisfação de seus direitos. Passa-se, então, a uma judicialização da política, sendo a saúde o principal exemplo desse fenômeno. Contudo, percebe-se que aqueles que conseguem acessar ao Poder Judiciário, acabam, na maioria das vezes, "obtendo mais" de um determinado direito, que outras que não ajuizaram ação. Assim, o que o Estado num primeiro momento não oferece à população, é depois concedido aos poucos que demandaram judicialmente - o que, em regra, acaba sendo mais custoso para o ente estatal, além de reforçar as desigualdades presentes neste país. A fim de evitar isso, é necessário observar as listas de serviços e medicamentos oferecidos pelo SUS, e respeitar o orçamento público, pois o conteúdo do direito à saúde está intimamente relacionado aos recursos financeiros disponíveis. 


\section{REFERÊNCIAS}

AURELIANO, Liana; DRAIBE, Sonia Miriam. A especificidade do "Welfare State" brasileiro. In MPAS e CEPAL. Economia e Desenvolvimento. Projeto: A política social em tempo de crise: articulação institucional e descentralização. Reflexões sobre a natureza do bem-estar. Brasília, 1989. p. 86-179.

BARROSO, Luís Roberto. Da falta de efetividade à judicialização excessiva: direito à saúde, fornecimento gratuito de medicamentos e parâmetros para a atuação judicial. Revista Jurídica UNIJUS, Uberaba, v. 11, n. 15, p. 13-38, nov. 2008.

BRANDÃO, Paulo de Tarso. Falta de recursos do estado, direitos fundamentais e escolhas democráticas. In: COUTINHO, Jacinto Nelson de Miranda; MORAIS, José Luis Bolzan de; STRECK, Lênio Luiz. Estudos Constitucionais. Rio de Janeiro: Renovar, 2007.

BRASIL. PORTARIA No 399, DE 22 DE FEVEREIRO DE 2006. Disponível em: <http://bvsms.saude.gov.br/bvs/saudelegis/gm/2006/prt0399_22_02_2006.html> Acesso em 04 ago. 2015.

BUSS, Paulo Marchiori. Saúde e desigualdade: o caso brasileiro. In: Paulo Marchiori Buss e Maria Eliana Labra (Orgs.). Sistemas de saúde: continuidades e mudanças. Rio de Janeiro, Editora Fiocruz, 1995.

CASSESE, Sabino. A crise do Estado. Campinas: Saberes Editora, 2010.

DALLARI, Sueli Gandolfi. Os Estados brasileiros e o direito à saúde. São Paulo: Editora Hucitec, 1995.

DEPARTAMENTO de atenção básica. Teto, credenciamento e implantação das estratégias de Agentes Comunitários de Saúde, Saúde da Família e Saúde Bucal Unidade Geográfica: Brasil. Acesso em 15 mar. 2016. Disponível em:

<http://dab.saude.gov.br/dab/historico_cobertura_sf/historico_cobertura_sf_relatorio.php>

ESPERA por consultas médicas para cirurgia aumenta em São Paulo. Folha de São Paulo. São Paulo, 4 ago. 2014. Disponível em:

$<$ http://www1.folha.uol.com.br/cotidiano/2014/08/1495292-espera-por-consultas-medicaspara-cirurgias-aumenta-em-sao-paulo.shtml>. Acesso em 15 jan. 2016

FIORI, José Luis. Estado de Bem-Estar Social: padrões e crises. PHYSYS: Rev. Saúde Coletiva. Rio de Janeiro, n.7, 1997, p. 129-147.

GARCÍA-PELAYO, Manuel. As transformações do estado contemporâneo. Rio de Janeiro: Forense, 2009.

KERSTENETZKY, Celia Lessa. O Estado do bem-estar social na idade da razão: a reinvenção do estado sicial no mundo contemporâneo. Rio de Janeiro: Elsevier, 2012.

MARQUES, Nádia Rejane. O direito à saúde: entre a norma e o fato. Porto Alegre: Nuria Fabris Editora, 2012. 
MINAS GERAIS. Tribunal de Justiça. Câmara Cível, 6. Agravo de Instrumento-Cv 1.0194.15.002310-0/003. Relatora: Des.(a) Claret de Moraes. Julgado em 16 fev. 2016. Disponível em: <www.tjmg.jus.br>. Acesso em: 02 abr. 2016.

MORAIS, José Luis Bolzan de. As crises do Estado e da Constituição e a transformação espaço-temporal dos direitos humanos. $2^{\mathrm{a}}$ ed. Porto Alegre: Livraria do Advogado, 2011.

MORAIS, José Luis Bolzan de; BRUM, Guilherme Valle. Políticas públicas e jurisdição constitucional: entre direitos, deveres e desejos. Porto Alegre: Livraria do Advogado, 2016.

NUNES, António José Avelãs; SCAFF, Fernando Facury. Os tribunais e o direito à saúde. Porto Alegre: Livraria do Advogado, 2011.

PIMENTA, Aparecida Linhares. O SUS e a municipalização à luz da experiência concreta. Disponível em: $<$ http://www.scielo.br/scielo.php?script=sci_arttext\&pid=S0104-

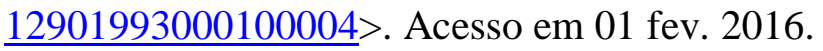

RIO DE JANEIRO. Tribunal de Justiça. Câmara Cível, 6. Apelação Cível no 004186705.2013.8.19.0004. Relator: Nagib Slaibi Filho. Julgado em 09 mar. 2016. Disponível em: <www.tjrj.jus.br>. Acesso em 02 abr. 2016.

RIO GRANDE DO SUL. Tribunal de Justiça. Câmara Cível, 21. Apelação Cível no 70056857972. Relator: Marco Aurélio Heinz. Julgado em 20 nov. 2013. Disponível em: <www.tjrs.jus.br>. Acesso em: 30 jan. 2015.

RISI JUNIOR, João Baptista; NOGUEIRA, Roberto Passos. As condições de saúde no Brasil. In: FINKELMAN, Jacob (Org.). Caminhos da saúde no Brasil. Rio de Janeiro: Editora Fiocruz, 2002.

ROSANVALLON, Pierre. A crise do Estado-Providência. Goiânia: Editora do UGF; Brasília: Editora da UnB, 1997.

SÃO PAULO. Tribunal de Justiça. Câmara de Direito Público, 13. Apelação Cível no 1019092-05.2014.8.26.0309. Relator: Djalma Lofrano Filho. Julgado: 30 mar. 2016. Disponível em: <www.tjsp.jus.br>. Acesso em: 02 mar. 2016.

SILVA, Hudson Pacifico da; VIANA, Ana Luiza d'Ávila. O financiamento do Sistema de Saúde no Brasil, gasto em saúde e as modalidades para sua racionalização. In: IBAÑEZ, Nelson; ELIAS, Paulo Eduardo Mangeon; SEIXAS, Paulo Henrique D’ Ângelo. Política e Gestão Pública em Saúde. São Paulo: Hucitec Editora, 2011.

STRECK, Lenio Luiz; MORAIS, José Luis Bolzan de. Ciência Política e Teoria Geral do Estado. Porto Alegre: Livraria do Advogado, 2000.

TORRES, Ricardo Lobo. As relações entre receita e despesa na Constituição. In: COUTINHO, Jacinto Nelson de Miranda; MORAIS, José Luis Bolzan de; STRECK, Lênio Luiz. Estudos Constitucionais. Rio de Janeiro: Renovar, 2007. 
VIANA, Ana Luiza d'Ávila; SILVA, Hudson Pacifico da. Economia e Saúde. In: IBAÑEZ, Nelson; ELIAS, Paulo Eduardo Mangeon; SEIXAS, Paulo Henrique D’Ângelo. Política e Gestão Pública em Saúde. São Paulo: Hucitec Editora, 2011. 